\title{
Data Protection and Privacy Regulations as an Inter-Active-Constructive Practice
}

\author{
Joseph Maguire \\ School of Computing Science \\ University of Glasgow \\ Glasgow, Scotland, United Kingdom \\ joseph.maguire@glasgow.ac.uk
}

\author{
Rosanne English \\ School of Information Sciences \\ University of Strathclyde \\ Glasgow, Scotland, United Kingdom \\ rosanne.english@strath.ac.uk
}

\author{
Steve Draper \\ School of Psychology \\ University of Glasgow \\ Glasgow, Scotland, United Kingdom \\ steve.draper@glasgow.ac.uk
}

\begin{abstract}
The aspiration of many governments around the world is to ensure all university graduates are well-versed in computing science and its related topics. This results in many graduates participating in postgraduate conversion courses. Many computing science schools favour delivering aspects of some topics, such as cyber security, simultaneously to students majoring in computing science and those converting to it. The challenge becomes integrating and understanding such a disparate student cohort. In this paper, we propose as a solution a learning design that has active, constructive and interactive elements. Student experience is reported and discussed, before considering the many benefits of the design.
\end{abstract}

\section{CCS CONCEPTS}

- Security and privacy $\rightarrow$ Privacy protections; • Social and professional topics $\rightarrow$ Computing education;

\section{KEYWORDS}

cyber security, privacy, active learning

\section{ACM Reference Format:}

Joseph Maguire, Rosanne English, and Steve Draper. 2019. Data Protection and Privacy Regulations as an Inter-Active-Constructive Practice. In Computing Education Practice (CEP '19), fanuary 9, 2019, Durham, United Kingdom. ACM, New York, NY, USA, 4 pages. https: //doi.org/10.1145/3294016.3294021

\section{INTRODUCTION}

Governments and businesses around the world are investing heavily in computing science and digital skills initiatives to

Permission to make digital or hard copies of all or part of this work for personal or classroom use is granted without fee provided that copies are not made or distributed for profit or commercial advantage and that copies bear this notice and the full citation on the first page. Copyrights for components of this work owned by others than the author(s) must be honored. Abstracting with credit is permitted. To copy otherwise, or republish, to post on servers or to redistribute to lists, requires prior specific permission and/or a fee. Request permissions from permissions@acm.org CEP '19, January 9, 2019, Durham, United Kingdom

(C) 2019 Copyright held by the owner/author(s). Publication rights licensed to ACM.

ACM ISBN 978-1-4503-6631-1/19/01.

https://doi.org/10.1145/3294016.3294021 secure economic growth. In the US, CS For All, CSFirst and $\mathrm{CS} 10 \mathrm{~K}$ represent billions of dollars of investment to improve access and the quality of computing science education [2]. In the UK, the Institute of Coding is a multimillion pound initiative between companies and higher education institutes to improve the digital skills of the nation [6]. The motivation is greater alignment between the requirements of industry and higher education institutions. Consequently, the focus is not only programming, but knowledge of other areas, such as data analysis and cyber security [11].

The challenge for many computing science departments, both in the UK and elsewhere is (1) considering the optimal learning design for content that is not programming-focused and (2) efficient and effective delivery of such content to majoring students as well as those converting from other disciplines. The reality is that most students majoring in computing science will possess the same level for certain topics, such as cyber security management, as those converting from other disciplines, i.e. very little [12]. Therefore, viable delivery for many institutions could be to deliver broadly the same content to majoring computing science students as well as those converting from other disciplines.

The challenge then becomes devising a learning design that not only stimulates all those involved but integrates very disparate students. Active learning designs, those devised to support audiences to collectively engage in the processing of information rather than simply receiving it, have the potential to stimulate and integrate audiences. Consequently, the contributions of this paper are:

- description of an active learning design for data protection and privacy regulations.

- report preliminary results and reaction from a cohort of 175 students.

- discussion surrounding the different objectives and benefits in adopting such a learning design.

\section{BACKGROUND}

Cooperstein and Kocevar-Weidinger argue that the foundation of active learning from a theoretical perspective is that of constructivist or discovery learning [4]. Cooperstein and Kocevar-Weidinger suggest, crucially, that in such a process 
there should be no lectures prior to any activity. Martín et al. suggests that fundamental to active learning is the collective processing and formation of knowledge or social constructivism [9]. Nevertheless, Good and Brophy would argue that the constructivist approach itself is only optimal when ideas are expressed and critiqued in partnership with others [5]. There are many different approaches or learning designs in computing science that attempt to embody these theories.

Maher et al. argue the flipped classroom is one such learning design, where students prepare in advance of class and then utilise a social constructivist approach to develop and refine knowledge in-class [8]. The flipped approach is interesting as students engage in consuming content and refining it, rather the creating. Alternatively, the Jigsaw approach, broadly, expects several class groups to investigate a component and then to regroup to consider the whole. The learning design was originally devised to address the challenge of segregation in 1970s US education [1]. Liao, Griswold and Porter report on the use of the learning design in a computing architecture course with students reporting deeper engagement and learning from the use of the design [7].

The challenge with many of the aforementioned active learning designs and many others in computing science is that the term and its effectiveness is often unclear [10]. Chi argues that active learning is poorly defined in general and attempts to provide clarity through a framework that distinguishes constructive, active and interactive learning activities as characterised by learner actions [3]. Chi reports that active activities are better than nothing, but interactive activities are likely more effective for learning. However, arguably learning designs can be devised by 'cherry-picking' active, interactive and constructive qualities.

Consequently, an optimal learning design for the current context could require students to interact and research in teams a specific topic, then construct an artefact that is actively presented or shared with the rest of the class. The aspiration is that by supporting students to interact and acknowledge contributions within teams, the lecturer can integrate and build community among disparate students. However, in addition the lecturer can learn from the presentations produced by teams in terms of the capability of the class and how to shape and respond to it.

\section{THE LEARNING DESIGN}

The activity was originally delivered in the first week of a Masters-level cyber security management course at a school of computing science within a research-led, ancient university. The class itself was in the first semester with a cohort of approximately 175 students with a diverse range of computing science backgrounds. While prior knowledge of computing science may vary among students, the assumption was the level of cyber security knowledge was similar.
The aim of the activity is to probe and develop understanding of data protection and privacy laws across the world. It requires students to complete the following: (1) self-organise into teams which represent a country, (2) research data protection and privacy laws for that country and (3) create and present a single presentation slide. The activity is designed to accommodate student motivation, by affording some choice in direction, as well as affording the course coordinator deeper insight into the knowledge of the class by inclusion of pre- and post-activity questionnaires.

For others to run the activity, it requires students to have access to systems and the Internet to investigate the topic and produce a presentation slide. The activity also requires production of a class activity sheet which details the aim and objectives of the activity and provides space for the student to write their name and team name so their forms can be returned to them after presenting. A pre- and postactivity questionnaire and a feedback form are also required. The activity sheet as well as the pre and post questionnaire should be stapled together to form a three-page activity pack which is provided to each student. A feedback form probing experience and reflection on the activity itself also must be provided to students.

In terms of structure, the initial step is to provide a signup sheet for students to select a team, or more specifically a country. Students are then required to gather into teams once the sign-up process has completed, with activity packs distributed to all individuals within teams once the class has settled. The purpose of the class activity is then explained in detail and individuals are then given 15 minutes to complete the pre-activity questionnaire. After the 15 minutes has elapsed, teams are instructed to return their activity packs to the course coordinator.

Teams are then instructed to spend time in the days between the current class and the next to investigate the topic and produce a single presentation slide which should be submitted to the lecturer either by email or ideally via a virtual learning environment (VLE).

The subsequent presentation session begins with the course coordinator distributing the bundles of activity packs. A single team member is then asked to present their team slide within a 2-minute window with the class instructed to clap the presenters off the stage if they run out of time. After the presentations, individuals are then instructed to spend 15 minutes reflecting on their answers from the previous session and how these may have changed (1) after their own investigation and (2) watching the presentations. Individuals are then instructed to complete the post-activity questionnaire. Once 15 minutes has elapsed, individuals should then be instructed to remove the cover sheet from the activity pack, thus making it anonymous, and return the stapled pre- 
and post-activity questionnaire. A feedback form for the activity is then distributed to individuals to gain additional insight into student perception of the activity.

\section{RESULTS}

The participants are here referred to by a participant identification number, e.g. "P18". 159 activity packs were returned by class participants with 103 consenting to their responses being shared, 10 of which were incomplete and 5 spoiled, resulting in 88 completed activity packs being considered.

Prior to team investigation, participants answered an openended question regarding motivation for selecting their team contained in the activity pack. Several themes emerged including that they had visited the country, were born there, lived and worked in the country for a time and/or had prior knowledge of country laws. However, P7 reflected the vast majority of respondents (48.9\%), stating that they were interested in learning more about the country: "I have heard a lot about Switzerland, but have never had the chance to actually visit the country. It interests me to know how the laws for the cyber world are put and managed compared to the ones present in my own country India."

The other prominent theme that emerged from participants regarding motivation $(10.4 \%)$ was ease and access to resources. P18 stated "Information in English and easily accessible". The surprise was that few participants (3.4\%) mentioned or referred to employment prospects or career aspirations as a motivation for selecting their team. Similarly, prior to team investigation, participants answered open-ended questions in broad terms what country they perceived as having the best as well as the most dangerous approach to data protection and privacy laws contained in the activity pack. The majority of students $(21.6 \%)$ stated that they perceived not a country, but the European Union as having the best approach to data protection, P76 reflected most students with "EU countries due to GDPR". Similarly, many participants (14.8\%) stated the United States had a good approach to data protection.

However, almost as many students (13.6\%) stated that they believed the United States had a dangerous approach to data protection and privacy. P74, though, reflected the vast majority of students (45.5\%) in stating that they perceived China as the country with the most dangerous approach to data protection and privacy: "China - restricted internet access and censorship" There were many comments of this nature from participants.

After observing presentations, the activity pack contained questions to determine any change in perception after engaging with the class activity. Interestingly, comparatively few students perceived (11.4\%) China as having the most dangerous approach after presentations. P74 changed from China to "Japan [as] little regulation". Indeed, the majority of participants (28.4\%) stated Russia was perceived as the most dangerous, an increase from the few participants $(4.6 \%)$ who identified it before presentations. Similarly, the majority of students changed from stating the European Union as the strongest on data protection and privacy to Germany $(22.7 \%)$ and Sweden (13.6\%). The increase is interesting as few students $(\sim 5 \%)$ identified either country prior to the presentations.

After the activity completed, a feedback form was circulated. The feedback forms are here referred to a feedback identification number, e.g. "F18". 141 feedback forms were returned with 97 participants consenting to sharing their responses. The participants were asked if they would have preferred anything in advance of the activity. Several themes emerged from the feedback forms, but the significant request was more information and resources that would support students in completing the activity. F67 stated "perhaps a handout on countries general approach to data protection. I didn't feel well versed on the issue". The participants were also asked if they wanted anything after the activity completed. The majority of students stated that they wanted the slides produced by their peers and wanted more feedback from the course coordinator as well as more discussion. Lastly, participants were asked if they had any other comments regarding the class activity. F39 reflected the majority of positive feedback from students: "overall positive and more 'involved' way of learning information intensive topic". Similarly, F54 stated "I liked a group activity early on in the course as it helped get to know people which can be difficult in a big lecture setting".

There was a lot of positive feedback to the class activity in terms of engagement and benefit, but there were still comments for improvement and criticism, with Feedback 43 (F43) crystallising the biggest concern, stating "didn't find [activity] to be useful towards a career in CS".

\section{DISCUSSION}

Like many learning designs, the approach reported here addressed multiple aims; and it is of interest to enumerate them, and especially to emphasise that they fall into different types. It may suggest to readers many different reasons for adopting some aspect of this design. The student feedback collected and reported above is consistent with all these objectives being achieved to a degree.

Objectives for what students will each learn:

- Appreciate that there are differences between dates at which legislation on privacy came into force (but actually, roughly only two groups of such dates).

- Appreciate that there are differences in content amongst countries, but in fact much less difference than most people realise. 
- Each student will get at least a little personal experience of finding such data on at least one country (a task they are quite likely to need to do in future jobs).

Objectives for how students will learn:

- Mode of conveying this overview knowledge. Enumerating 25 countries worth of data would be boring and inappropriate in a lecture, when it is the overall pattern that is the real message, plus access to skim-reading the details to see overall patterns. The slides produced by each group provide this data set in appropriate summary form.

- Allowing significant student choice on which single country to focus on allows many students to connect this bit of learning to their individual interests - generally increasing motivation.

Objectives for what the teacher will learn:

- What students' prior conceptions or assumptions on this topic are; and how those changed. Constructivism urges teachers to discover prior misconceptions in order to tailor their teaching not only to the desired final state, but to relate it to previous ideas.

Objectives for saving work for the teacher:

- Researching 25 countries' legislation would be a lot of work, and require refreshing every year. Here, the students provide this, and other students can check it if they doubt it since they have done similar "research" themselves.

Social objectives: not about content, but about changing intra-class relationships to support enhanced learning for the rest of the course and to make peer collaboration outside contact hours more likely:

- Working in a group they chose themselves on a topic usually of common interest, gives an early experience of bonding with at least some students in the class, while accommodating students' initial preferences for being with similar people.

- Turning the student diversity within the class from a potential problem into a positive contribution. Because the topic is about contrasts between countries, hearing from different nationalities is relevant and so a plus.

- Receiving relevant content from other groups tends to boost perceptions of others as potential sources of assistance (as in the original Jigsaw design [1], and other uses of student generated content).

- So many students being required to give a presentation (although only of 2 minutes) fosters both bonding in the face of common adversity, and the sense of the class being in this together.
- Furthermore it sets a precedent of any/all students speaking out in class, in front of everyone: good for future Q\&A in class.

\section{CONCLUSION}

There are challenges in devising the optimal learning design for cyber security in computing science. The situation is exacerbated as courses can be delivered to both students majoring in the discipline and those converting to it. Devising a learning design, from the perspective of Chi, that is interactive, active and constructive in nature has numerous benefits, not only for staff and students, but also in terms of achieving more than the typical intended learning outcomes.

\section{REFERENCES}

[1] Elliot Aronson and Diane Bridgeman. 1979. Jigsaw groups and the desegregated classroom: In pursuit of common goals. Personality and social psychology bulletin 5, 4 (1979), 438-446.

[2] Owen Astrachan, Jan Cuny, Chris Stephenson, and Cameron Wilson. 2011. The CS10K Project: Mobilizing the Community to Transform High School Computing. In Proceedings of the 42Nd ACM Technical Symposium on Computer Science Education (SIGCSE '11). ACM, New York, NY, USA, 85-86. https://doi.org/10.1145/1953163.1953193

[3] Michelene TH Chi. 2009. Active-constructive-interactive: A conceptual framework for differentiating learning activities. Topics in cognitive science 1, 1 (2009), 73-105.

[4] Susan E Cooperstein and Elizabeth Kocevar-Weidinger. 2004. Beyond active learning: a constructivist approach to learning. Reference Services Review 32, 2 (2004), 141-148.

[5] T Good and J Brophy. 2003. Looking in classrooms. Allyn and Bacon, Boston, MA.

[6] UK Government. 2018. Prime Minister announces £20 million Institute of Coding. https://www.gov.uk/government/news/ prime-minister-announces-20-million-institute-of-coding. [Online: accessed 22-September-2018].

[7] Soohyun Nam Liao, William G. Griswold, and Leo Porter. 2018. Classroom Experience Report on Jigsaw Learning. In Proceedings of the 23rd Annual ACM Conference on Innovation and Technology in Computer Science Education (ITiCSE 2018). ACM, New York, NY, USA, 302-307. https://doi.org/10.1145/3197091.3197118

[8] Mary Lou Maher, Celine Latulipe, Heather Lipford, and Audrey Rorrer. 2015. Flipped classroom strategies for CS education. In Proceedings of the 46th ACM Technical Symposium on Computer Science Education. ACM, New York, 218-223.

[9] Estefanía Martín, Carlos Lázaro, and Isidoro Hernán-Losada. 2010. Active learning in telecommunication engineering: A case study. In Proceedings IEEE EDUCON. IEEE, New York, 1555-1562.

[10] Kate Sanders, Jonas Boustedt, Anna Eckerdal, Robert McCartney, and Carol Zander. 2017. Folk pedagogy: Nobody doesn't like active learning. In Proceedings of the 2017 ACM Conference on International Computing Education Research. ACM, New York, 145-154.

[11] Ambareen Siraj, Blair Taylor, Siddarth Kaza, and Sheikh Ghafoor. 2015. Integrating Security in the Computer Science Curriculum. ACM Inroads 6, 2 (May 2015), 77-81. https://doi.org/10.1145/2766457

[12] Blair Taylor and Siddharth Kaza. 2016. Security Injections\&Commat;Towson: Integrating Secure Coding into Introductory Computer Science Courses. Trans. Comput. Educ. 16, 4, Article 16 (June 2016), 20 pages. https://doi.org/10.1145/2897441 